\title{
Plasma-initiated rehydrogenation of amorphous silicon to increase the temperature processing window of silicon heterojunction solar cells
}

Jianwei Shi, Mathieu Boccard, and Zachary Holman

Citation: Appl. Phys. Lett. 109, 031601 (2016); doi: 10.1063/1.4958831

View online: http://dx.doi.org/10.1063/1.4958831

View Table of Contents: http://aip.scitation.org/toc/apl/109/3

Published by the American Institute of Physics

\section{Articles you may be interested in}

Asymmetric band offsets in silicon heterojunction solar cells: Impact on device performance Journal of Applied Physics 120, 054501 (2016); 10.1063/1.4959988

Passivation mechanism in silicon heterojunction solar cells with intrinsic hydrogenated amorphous silicon oxide layers

Journal of Applied Physics 121, 085306 (2017); 10.1063/1.4977242

Light-induced performance increase of silicon heterojunction solar cells

Applied Physics Letters 109, 153503 (2016); 10.1063/1.4964835

Improved amorphous/crystalline silicon interface passivation by hydrogen plasma treatment Applied Physics Letters 99, 123506 (2011); 10.1063/1.3641899

Understanding the thickness-dependent effective lifetime of crystalline silicon passivated with a thin layer of intrinsic hydrogenated amorphous silicon using a nanometer-accurate wet-etching method

Journal of Applied Physics 119, 235307 (2016); 10.1063/1.4954069

Silicon heterojunction solar cell with passivated hole selective $\mathrm{MoO}_{\mathrm{x}}$ contact

Applied Physics Letters 104, 113902 (2014); 10.1063/1.4868880

\section{A D | Applied Physics Letters}

If your article has the

potential to shape the future of

Save your money for your research.

It's now FREE to publish with us no page, color or publication charges apply. applied physics, it BELONGS in

Applied Physics Letters 


\title{
Plasma-initiated rehydrogenation of amorphous silicon to increase the temperature processing window of silicon heterojunction solar cells
}

\author{
Jianwei Shi, Mathieu Boccard, and Zachary Holman \\ School of Electrical, Computer, and Energy Engineering, Arizona State University, Tempe, \\ Arizona 85287-5706, USA
}

(Received 10 April 2016; accepted 2 July 2016; published online 19 July 2016)

\begin{abstract}
The dehydrogenation of intrinsic hydrogenated amorphous silicon (a-Si:H) at temperatures above approximately $300^{\circ} \mathrm{C}$ degrades its ability to passivate silicon wafer surfaces. This limits the temperature of post-passivation processing steps during the fabrication of advanced silicon heterojunction or silicon-based tandem solar cells. We demonstrate that a hydrogen plasma can rehydrogenate intrinsic a-Si:H passivation layers that have been dehydrogenated by annealing. The hydrogen plasma treatment fully restores the effective carrier lifetime to several milliseconds in textured crystalline silicon wafers coated with 8-nm-thick intrinsic a-Si:H layers after annealing at temperatures of up to $450^{\circ} \mathrm{C}$. Plasma-initiated rehydrogenation also translates to complete solar cells: A silicon heterojunction solar cell subjected to annealing at $450^{\circ} \mathrm{C}$ (following intrinsic a-Si:H deposition) had an open-circuit voltage of less than $600 \mathrm{mV}$, but an identical cell that received hydrogen plasma treatment reached a voltage of over $710 \mathrm{mV}$ and an efficiency of over $19 \%$. Published by AIP Publishing. [http://dx.doi.org/10.1063/1.4958831]
\end{abstract}

Amorphous silicon/crystalline silicon heterojunction (SHJ) solar cells have the highest conversion efficiencies amongst all silicon solar cells, ${ }^{1}$ notably due to their opencircuit voltages $\left(V_{o c} \mathrm{~s}\right)$ of up to $750 \mathrm{mV} .^{2}$ The high $V_{o c} \mathrm{~s}$ are attributed to the surface passivation quality of the thin intrinsic hydrogenated amorphous silicon (a-Si:H) layers, which effectively decrease the defect density at the crystalline silicon (c-Si) surface. However, this passivation degrades when heating the wafer at elevated temperatures because hydrogen effuses from the a-Si:H layers. ${ }^{3}$ While the ability to make good SHJ solar cells at low temperatures (below $250^{\circ} \mathrm{C}$ ) is usually presented as an advantage, this restriction on the temperature of the processing steps following a-Si:H deposition is also a limitation. For example, it prevents the use of silicon nitride passivating and anti-reflection layers that are usually deposited at $350^{\circ} \mathrm{C}$, as well as the use of hightemperature, low-resistivity silver pastes that are typically annealed at over $400^{\circ} \mathrm{C}$. Also, it imposes restrictions on future tandem devices with a SHJ bottom cell, since many top cell candidates require high-temperature steps (e.g., above $\left.400^{\circ} \mathrm{C}\right) .^{4-7}$ Ideally, intrinsic a-Si:H layers would continue to provide excellent passivation after processing at temperatures of at least $400^{\circ} \mathrm{C}$.

One temperature-resistant alternative to a-Si:H is lowcarbon-content $\mathrm{a}-\mathrm{SiC}_{\mathrm{x}}: \mathrm{H}$ : up to $350^{\circ} \mathrm{C}$ temperature tolerance has been demonstrated with good cell performance. ${ }^{8}$ However, the incorporation of carbon also increases the defect density at the interface, establishing a tradeoff between high-temperature stability (high carbon content) and excellent passivation (low carbon content). Another approach to obtain excellent and stable passivation is to replace the intrinsic a$\mathrm{Si}: \mathrm{H}$ layer with a very thin silicon oxide layer, allowing charges to be collected by tunneling. ${ }^{9}$ This approach has been particularly successful for electron-selective contacts but still underperforms compared to a-Si:H for hole-selective contacts, and it requires sub-nanometer precision for the oxide thickness. ${ }^{9}$ Also, this temperature-resilient passivation approach actually requires a $800-900{ }^{\circ} \mathrm{C}$ annealing step for the crystallization of the doped layer capping the silicon oxide layer. $^{9}$

As an alternative to replacing the a-Si:H layer, hydrogen can be reintroduced after high-temperature annealing. Nickel and Jackson showed that post-annealing hydrogenation of a-Si:H greatly increases the $\mathrm{Si}-\mathrm{H}$ bond density without changing the layer's annealed defect density, its weak-bond density, or its metastability. ${ }^{10}$ Indeed, the luminescence characteristics of a thermally dehydrogenated $0.3-\mu \mathrm{m}$-thick a-Si:H layer were restored by rehydrogenating it. ${ }^{11}$ Recently, the passivation provided by as-deposited 7-nm-thick or 15-nm-thick intrinsic a-Si:H layers was demonstrated to improve upon performing a hydrogen plasma treatment, ${ }^{12,13}$ and the passivation of 35-105-nm-thick a-Si:H layers was shown to recover after a high-peak-temperature processing step by annealing in an atmosphere consisting of molecular and atomic hydrogen. ${ }^{14}$ We investigate here the possibility of restoring the passivation provided by thin, device-relevant intrinsic a-Si:H layers after high-temperature annealing. We apply hydrogen plasma treatments to rehydrogenate 6-20nm-thick a-Si:H layers after $20 \mathrm{~min}$ annealing at $300-600{ }^{\circ} \mathrm{C}$. We also integrate the dehydrogenation and rehydrogenation (i.e., annealing and hydrogen plasma treatment) processes into the fabrication of complete SHJ solar cells to demonstrate compatibility with devices.

Except where otherwise stated, 200- $\mu$ m-thick, $1-5 \Omega \mathrm{cm}$ n-type monocrystalline Czochralski silicon wafers were used as substrates. Wafers were textured in an alkaline solution to form random pyramids, cleaned in piranha and RCA-B solutions, and then dipped in buffered oxide etch (BOE) prior to a-Si:H deposition. Identical intrinsic a-Si:H layers were deposited $^{15}$ on both sides of the wafers, the wafers were then annealed to dehydrogenate the a-Si:H layers, and hydrogen plasma treatments were finally performed on both sides of the 
wafers to rehydrogenate the symmetric a-Si:H layers. Both the intrinsic a-Si:H depositions $(60 \mathrm{~W}, 3.2$ Torr, $40 \mathrm{sccm}$ silane, and $200 \mathrm{sccm}$ hydrogen) and the hydrogen plasma treatments $(60 \mathrm{~W}, 3.5$ Torr, $500 \mathrm{sccm}$ hydrogen) were conducted at $250^{\circ} \mathrm{C}$ in a plasma-enhanced chemical vapor deposition (PECVD) tool, and the annealing was done at $300-600{ }^{\circ} \mathrm{C}$ for $20 \mathrm{~min}$ in a box furnace with ambient air. For complete SHJ cells, p- and n-type a-Si:H films were deposited over the intrinsic layers, ${ }^{15}$ indium tin oxide (ITO) layers were sputtered on both sides, a silver electrode was sputtered on the rear, a silver grid was screen printed on the front, and the samples were finally annealed at $240^{\circ} \mathrm{C}$ to cure the silver paste. Several $4 \mathrm{~cm}^{2}$ cells were made on each wafer using a shadow mask during sputtering and a dedicated screen during printing.

Effective minority carrier lifetimes were measured with a Sinton photoconductance-decay lifetime tester. The thickness and bandgap of the intrinsic a-Si:H films were determined with a Tauc-Lorentz model fit to spectroscopic ellipsometry data taken on polished wafers that were used as witnesses in select experiments. To achieve the same a-Si:H layer thickness on textured wafers as that measured on polished wafers, the deposition time was increased by a factor of 1.6, which is an intermediate value between the scaling factor of 1.5 that we previously measured ${ }^{15}$ and the factor of 1.7 that is found in the literature. ${ }^{16}$ The thicknesses reported are thus those on textured wafers, as calculated from the measurements on polished wafers. A continuous-illumination Newport sun simulator was used to acquire current-voltage (I-V) characteristics under AM 1.5G $\left(100 \mathrm{~mW} / \mathrm{cm}^{2}\right)$ illumination. The implied $V_{o c}$ was extracted using a Sinton lifetime tester before ITO sputtering and silver metallization. The pseudo fill factor was extracted from a Sinton Suns-Voc tester. Note that, in some experiments, wafers were removed from the PECVD tool for lifetime measurements and annealing, and then reintroduced into the PECVD tool for additional hydrogen plasma treatment. In this case, the wafers were dipped in BOE again before loading into the PECVD tool to remove any native oxide.

Figure 1 shows the bandgap and thickness of intrinsic $\mathrm{a}-\mathrm{Si} \mathrm{H}$ layers on polished wafers after each of the processing steps investigated in this paper. The initial bandgap of $1.69 \mathrm{eV}$ - which is typical for device-quality a-Si:Hdecreases by $0.08 \mathrm{eV}$ after annealing at $400^{\circ} \mathrm{C}$, which is consistent with a reduction in the hydrogen fraction in the film from $15.0 \pm 2.5 \%$ to $8.5 \pm 2.5 \% .{ }^{17}$ After subsequent application of a hydrogen plasma for $2 \mathrm{~min}$, the bandgap widens to $1.89 \mathrm{eV}$, corresponding to a hydrogen fraction of $33 \pm 3 \% .^{17}$ This dehydrogenation and rehydrogenation was also confirmed in a separate Fourier transform infrared spectroscopy experiment (not shown here), but these measurements required double-side polished c-Si wafers with 40-nm-thick a-Si:H layers to obtain sufficient signal. Whereas hydrogen effuses from the film upon annealing at $400^{\circ} \mathrm{C}$ as weak $\mathrm{Si}-\mathrm{H}$ bonds break, atomic hydrogen diffuses into the film upon treatment with a plasma that dissociates the molecular hydrogen precursor gas. ${ }^{18}$ However, hydrogen plasma treatment also etches the film, ${ }^{12,19}$ with a $2 \mathrm{~nm} / \mathrm{min}$ rate in this case (Figure 1). As intrinsic a-Si:H layers that are thinner than approximately $5 \mathrm{~nm}$ poorly passivate c-Si surfaces, ${ }^{20-23}$ prolonged hydrogen

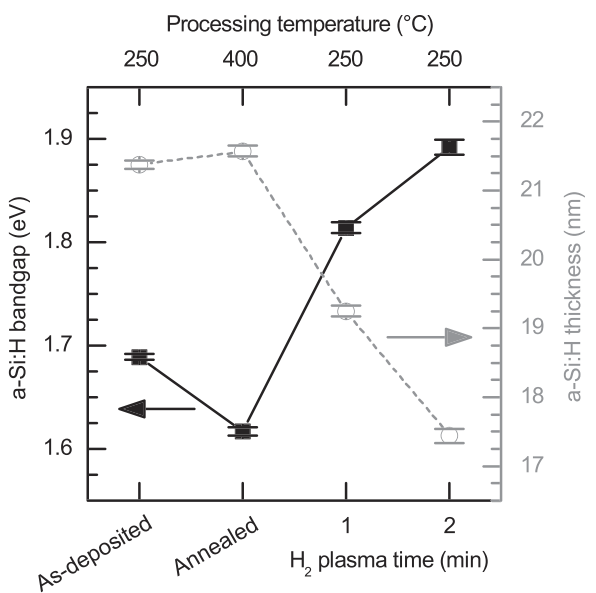

FIG. 1. Bandgap and thickness of intrinsic a-Si:H layers on a polished c-Si wafer. Data are shown for the as-deposited state, after annealing at $400{ }^{\circ} \mathrm{C}$ for $20 \mathrm{~min}$, and after hydrogen plasma treatment. The a-Si:H layers were deposited on one wafer which was then broken into four pieces that were processed as indicated on the $\mathrm{x}$-axis. The results were obtained by fitting ellipsometry measurements with a Tauc-Lorentz model; the error bars represent the $90 \%$ confidence intervals of the fits.

plasma treatment on a-Si:H layers should be avoided during SHJ cell processing.

Figure 2 investigates the minority-carrier effective lifetime in textured wafers passivated with symmetric intrinsic a-Si:H layers as they undergo the dehydrogenation and rehydrogenation observed in Figure 1. For all a-Si:H film thicknesses, the lifetime degrades upon annealing at $400^{\circ} \mathrm{C}$, and it can be partially or fully restored upon hydrogen plasma exposure for $1 \mathrm{~min}$ or less. Excellent surface passivationresulting in lifetimes of up to $6 \mathrm{~ms}$ - can be achieved by rehydrogenating the 20-nm-thick a-Si:H layers, even after (partial) dehydrogenated at $400{ }^{\circ} \mathrm{C}$; for more device-relevant a-Si:H thicknesses $(6-10 \mathrm{~nm})$, the lifetime recovery upon rehydrogenation is still noteworthy. This lifetime enhancement is attributed to the diffusion of atomic hydrogen to the $\mathrm{a}-\mathrm{Si} \mathrm{H} / \mathrm{c}-\mathrm{Si}$ interface and the associated reduction of dangling bond density. ${ }^{13}$ For the same processing condition, thinner a-Si:H layers result in lower lifetimes, likely because there is less hydrogen in a thin a-Si:H layer that can transfer from a higher hydride state within the film to a monohydride

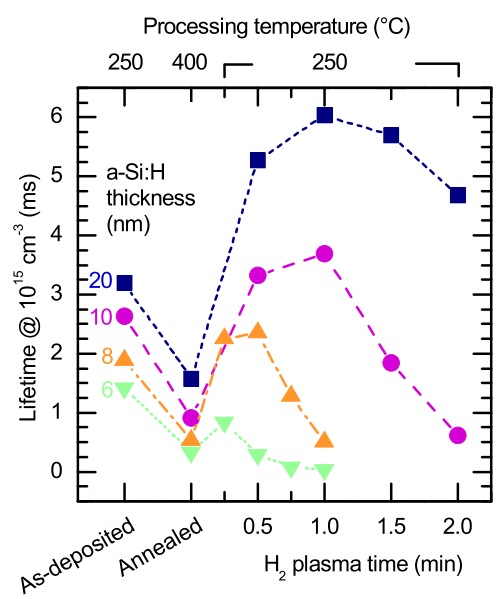

FIG. 2. Effective lifetimes of textured c-Si wafers with 6- to 20-nm-thick intrinsic a-Si:H layers on both sides. Data are shown for the as-deposited state, after annealing at $400^{\circ} \mathrm{C}$ for $20 \mathrm{~min}$, and after hydrogen plasma treatment. 
surface state at the a-Si:H/c-Si interface. ${ }^{24}$ Prolonged hydrogen plasma treatment also reduces lifetime, especially for thin a-Si:H layers. Consistent with many other reports, ${ }^{20-23}$ we find that at least $5 \mathrm{~nm}$ of a-Si:H is necessary for millisecond lifetimes; otherwise, the a-Si:H layers after hydrogen etching are too thin to prevent tunneling to the defective surface $^{25}$ and the underlying c-Si substrate can be damaged by the hydrogen plasma. ${ }^{3,19}$ For device applications, a 30 -s hydrogen plasma treatment on an 8-nm-thick a-Si:H layer appears to be a good recipe because the implied $V_{o c}$ and implied voltage at maximum power point $\left(V_{m p p}\right)$ are enhanced by $35 \mathrm{mV}$ and $50 \mathrm{mV}$, respectively, compared to the annealed state. Samples with thicker a-Si:H layers have higher lifetime upon slightly longer hydrogen plasma treatment, but they incur more optical and resistive losses that result in lower device efficiency. ${ }^{20}$

To find the maximum tolerable post-passivation temperature that still allows for successful lifetime recovery upon rehydrogenation, we annealed textured wafers symmetrically passivated with 8-nm-thick intrinsic a-Si:H layers at $400-500{ }^{\circ} \mathrm{C}$ and subsequently performed hydrogen plasma treatments (Figure 3). The annealing temperature strongly affects the rate at which hydrogen evolves from a-Si:H deposited by PECVD: for example, the evolution rate at $510^{\circ} \mathrm{C}$ was shown to be ten times higher than that at $300{ }^{\circ} \mathrm{C} .^{26}$ Hydrogen evolution has been reported to begin occurring at temperatures between $250{ }^{\circ} \mathrm{C}^{26}$ and $350{ }^{\circ} \mathrm{C},{ }^{18}$ but we observed prominent lifetime degradation only at $400^{\circ} \mathrm{C}$ and above, consistent with previous results on 20-nm-thick a-Si:H layers. ${ }^{8}$ As shown in Figure $3,450^{\circ} \mathrm{C}$ is the maximum temperature after which $>1 \mathrm{~ms}$ lifetime can be recovered via hydrogen plasma treatment. At this temperature, the effect of rehydrogenation is dramatic: the post-annealing lifetime is only $64 \mu \mathrm{s}$, and thus the implied $V_{o c}$ jumps from $614 \mathrm{mV}$ to $722 \mathrm{mV}$ with a 30-s hydrogen plasma treatment. However, the post-annealing lifetime enhancement becomes less prominent at an annealing temperature of $500{ }^{\circ} \mathrm{C}$. We suspect this is mainly due to the adverse hydrogen etching during hydrogen plasma treatment: too much dehydrogenation makes the optimum rehydrogenation time (i.e., the time to get back to $>15 \%$ hydrogen content) longer than what it takes to etch away a few nanometers. Indeed, for

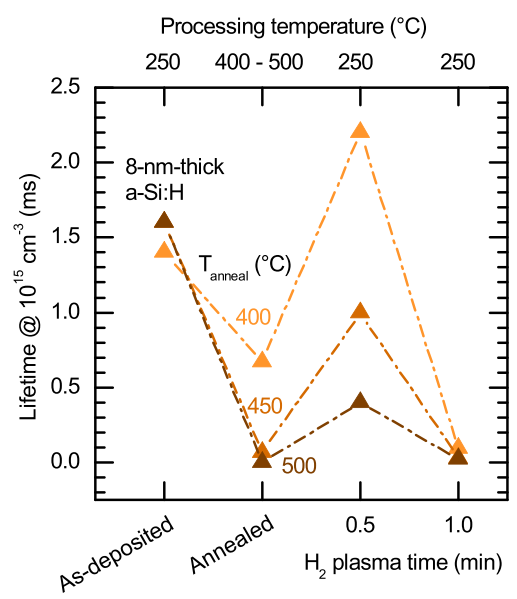

FIG. 3. Effective lifetimes of textured c-Si wafers with 8-nm-thick intrinsic a-Si:H on both sides. Data are shown for the as-deposited state, after annealing at $400-500^{\circ} \mathrm{C}$ for $20 \mathrm{~min}$, and after hydrogen plasma treatment. annealing temperatures beyond $500^{\circ} \mathrm{C}$ (not shown), the hydrogen plasma treatment fails to provide any substantial lifetime recovery. As the annealing temperature exceeds $500^{\circ} \mathrm{C}$, the a$\mathrm{Si}: \mathrm{H}$ layer is also likely to be crystallized. For example, the ellipsometry data of a 15-nm-thick a-Si:H layer after annealing at $600^{\circ} \mathrm{C}$ cannot be fit with a standard Tauc-Lorentz model.

We next tested the rehydrogenation of intrinsic a-Si:H layers exposed to a high-temperature step in complete SHJ solar cells to evaluate the compatibility of this process with real devices. All solar cells were identically fabricated, except each underwent one of four different steps directly following the deposition of the intrinsic a-Si:H layers: (i) no treatment; (ii) annealing at $450^{\circ} \mathrm{C}$ for $20 \mathrm{~min}$; (iii) annealing at $450^{\circ} \mathrm{C}$ for $20 \mathrm{~min}$ and then $30 \mathrm{~s}$ of hydrogen plasma treatment; or (iv) $30 \mathrm{~s}$ of hydrogen plasma treatment. The $V_{o c}$, fill factor $(F F)$, short-circuit current density $\left(J_{s c}\right)$, and efficiency of these cells are shown in Figure 4. The $F F$ and $J_{s c}$ are statistically similar for all four cell types, but the implied and actual $V_{o c} \mathrm{~s}$ are quite different. Note that our current baseline SHJ cell processing uses the fourth type, which gives better surface passivation than the first type (no hydrogen plasma treatment). ${ }^{12,13}$ The first three types of cells show that-as anticipated from the lifetime measurements in Figures 2 and 3dehydrogenation greatly degrades the implied and actual $V_{o c}$ s, and rehydrogenation recovers them. Comparing the third and the fourth types reveals that rehydrogenation via hydrogen plasma treatment after dehydrogenation via annealing not only enables millisecond passivation but also does not negatively impact light absorption and carrier transport. The

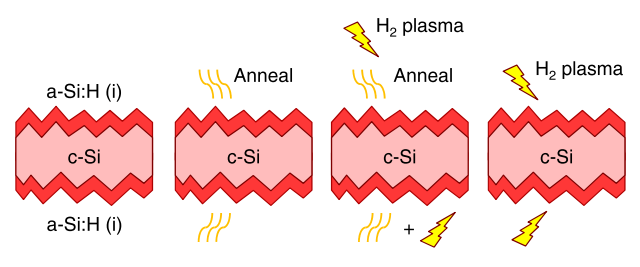

(i)

(ii)

(iii)

(iv)

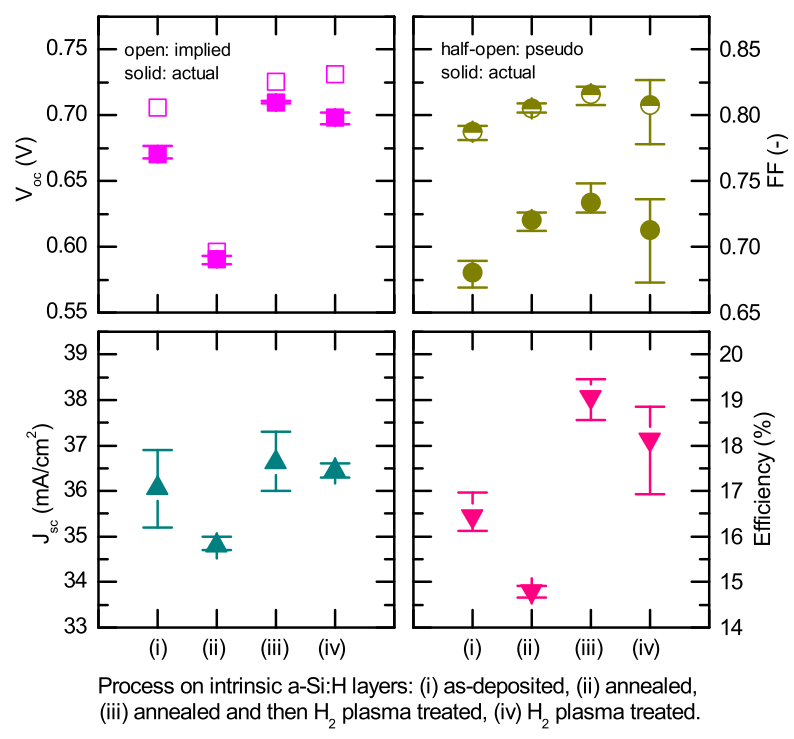

FIG. 4. Performance of SHJ solar cells with varying treatments following deposition of the intrinsic a-Si:H layers (schematic diagram at the top). Each symbol represents the average value of three $4 \mathrm{~cm}^{2}$ cells on the same wafer, and the error bars indicate the maximum and minimum values. 
efficiency of the third type of SHJ cell exceeds $19 \%$ and is statistically equivalent to the fourth type (reference cell).

Hydrogen plasma treatment can thus be used to recover the surface passivation of greater-than-8-nm-thick intrinsic a-Si:H layers after annealing at temperatures of up to $450^{\circ} \mathrm{C}$. This plasma-initiated rehydrogenation strategy provides a path to widening the processing window of SHJ cells, which would enable compatibility with high-temperature pastes, layers, and top cells. In addition, rehydrogenation via hydrogen plasma may be applicable to other passivation materials, such as a- $\mathrm{SiN}_{\mathrm{x}}: \mathrm{H}^{27}$ and $\mathrm{a}-\mathrm{SiO}_{\mathrm{x}:} \mathrm{H},{ }^{28}$ and other substrates, such as $\mathrm{GaN}^{29}$ and InP. ${ }^{30}$ Rehydrogenation would be most beneficial, however, if the hydrogen plasma treatment step could be applied to complete cells-or at least after the deposition of the doped a-Si:H layers-since high temperatures that would cause dehydrogenation are often used towards the end of cell fabrication. This study is a first step towards this goal, and motivates further investigation to unravel the interaction of hydrogen with intrinsic/doped a-Si:H layers stacks and transparent conductive oxide layers.

We acknowledge Kate Fisher, Zhengshan (Jason) Yu, and Mehdi Leilaeioun for their support in wafer preparation and solar cell processing. This material is based upon work primarily supported by the Engineering Research Center Program of the National Science Foundation and the Office of Energy Efficiency and Renewable Energy of the Department of Energy under NSF Cooperative Agreement No. EEC-1041895. The information, data, or work presented herein is also funded in part by the U.S. Department of Energy, Energy Efficiency and Renewable Energy Program, under Award No. DE-EE0006335. The support was also provided by the Research Corporation for Science Advancement through Scialog Collaborative Innovation Award No. 23460.

${ }^{1}$ K. Masuko, M. Shigematsu, T. Hashiguchi, D. Fujishima, M. Kai, N. Yoshimura, T. Yamaguchi, Y. Ichihashi, T. Mishima, N. Matsubara, T. Yamanishi, T. Takahama, M. Taguchi, E. Maruyama, and S. Okamoto, IEEE J. Photovoltaics 4, 1433-1435 (2014); M. Taguchi, A. Yano, S. Tohoda, K. Matsuyama, Y. Nakamura, T. Nishiwaki, K. Fujita, and E. Maruyama, in Proceedings of the 39th IEEE Photovoltaic Specialist Conference (PVSC) (IEEE, Tampa Bay 2013), pp. 96-99.

${ }^{2}$ S. Y. Herasimenka, W. J. Dauksher, and S. G. Bowden, Appl. Phys. Lett. 103, 053511 (2013).
${ }^{3}$ R. A. Street, Hydrogenated Amorphous Silicon (Cambridge University Press, 1991).

${ }^{4}$ P. Qin, S. Tanaka, S. Ito, N. Tetreault, K. Manabe, H. Nishino, M. K. Nazeeruddin, and M. Grätzel, Nat. Commun. 5, 3834 (2014).

${ }^{5}$ N. C. Strandwitz, D. B. Turner-Evans, A. C. Tamboli, C. T. Chen, H. A. Atwater, and N. S. Lewis, Adv. Energy Mater. 2, 1109 (2012).

${ }^{6}$ K. N. Yaung, J. R. Lang, and M. L. Lee, in Proceedings of the 40th IEEE Photovoltaic Specialist Conference (PVSC) (IEEE, Denver, 2014), pp. 0831-0835.

${ }^{7}$ K. Tanabe, A. Fontcuberta i Morral, H. A. Atwater, D. J. Aiken, and M. W. Wanlass, Appl. Phys. Lett. 89, 102106 (2006).

${ }^{8}$ M. Boccard and Z. C. Holman, J. Appl. Phys. 118, 065704 (2015).

${ }^{9}$ F. Feldmann, M. Simon, M. Bivour, C. Reichel, M. Hermle, and S. W. Glunz, Appl. Phys. Lett. 104, 181105 (2014); F. Feldmann, M. Bivour, C. Reichel, M. Hermle, and S. W. Glunz, Sol. Energy Mater. Sol. Cells 120, 270-274 (2014); A. Moldovan, F. Feldmann, M. Zimmer, J. Rentsch, J. Benick, and M. Hermle, ibid. 142, 123-127 (2015).

${ }^{10}$ N. H. Nickel and W. B. Jackson, J. Non-Cryst. Solids 164-166, 281-284 (1993).

${ }^{11}$ J. I. Pankove, Appl. Phys. Lett. 32, 812 (1978).

${ }^{12}$ A. Descoeudres, L. Barraud, S. De Wolf, B. Strahm, D. Lachenal, C. Guérin, Z. C. Holman, F. Zicarelli, B. Demaurex, J. Seif, J. Holovsky, and C. Ballif, Appl. Phys. Lett. 99, 123506 (2011).

${ }^{13}$ M. Mews, T. F. Schulze, N. Mingirulli, and L. Korte, Appl. Phys. Lett. 102, 122106 (2013).

${ }^{14}$ S. Gloger, N. Brinkmann, and B. Terheiden, Energy Procedia 8, 666-671 (2011).

${ }^{15}$ S. Y. Herasimenka, Ph.D. thesis, Arizona State University, Tempe, 2013.

${ }^{16} \mathrm{~S}$. Olibet, Ph.D. thesis, Universit'e de Neuchâtel, Neuchâtel, 2009.

${ }^{17}$ T. F. Schulze, L. Korte, F. Ruske, and B. Rech, Phys. Rev. B 83, 165314 (2011); C. G. Van de Walle and L. Yang, J. Vac. Sci. Technol., B 13, 1635 (1995).

${ }^{18}$ J. I. Pankove, M. A. Lampert, and M. L. Tarng, Appl. Phys. Lett. 32, 439 (1978).

${ }^{19}$ J. Geissbühler, S. De Wolf, B. Demaurex, J. P. Seif, D. T. Alexander, L. Barraud, and C. Ballif, Appl. Phys. Lett. 102, 231604 (2013).

${ }^{20}$ Z. C. Holman, A. Descoeudres, L. Barraud, F. Z. Fernandez, J. P. Seif, S. De Wolf, and C. Ballif, IEEE J. Photovoltaics 2, 7-15 (2012).

${ }^{21}$ H. Fujiwara and M. Kondo, J. Appl. Phys. 101, 054516 (2007).

${ }^{22}$ M. Tanaka, M. Taguchi, T. Matsuyama, T. Sawada, S. Tsuda, S. Nakano, H. Hanafusa, and Y. Kuwano, Jpn. J. Appl. Phys., Part 1 31, 3518-3522 (1992).

${ }^{23}$ N. Jensen, R. M. Hausner, R. B. Bergmann, J. H. Werner, and U. Rau, Prog. Photovoltaics 10, 1-13 (2002).

${ }^{24}$ S. De Wolf and M. Kondo, J. Appl. Phys. 105, 103707 (2009).

${ }^{25}$ T. F. Schulze, C. Leendertz, N. Mingirulli, L. Korte, and B. Rech, Energy Procedia 8, 282-287 (2011).

${ }^{26}$ D. K. Biegelsen, R. A. Street, C. C. Tsai, and J. C. Knights, Phys. Rev. B 20, 4839 (1979).

${ }^{27}$ A. G. Aberle, Sol. Energy Mater. Sol. Cells 65, 239-248 (2001).

${ }^{28}$ G. Dingemans, W. Beyer, M. C. M. van de Sanden, and W. M. M. Kessels, Appl. Phys. Lett. 97, 152106 (2010).

${ }^{29}$ A. Hierro and S. A. Ringel, Appl. Phys. Lett. 77, 1499 (2000).

${ }^{30}$ J. Chevallier, A. Jalil, B. Theys, J. C. Pesant, M. Aucouturier, B. Rose, and A. Mircea, Semicond. Sci. Technol. 4, 87-90 (1989). 